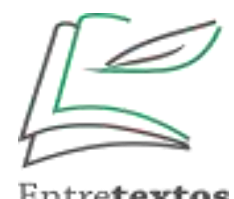

Entretextos 21(3): especial, 2021

ISSN (digital): 2764-0809

ISSN (impresso): 1519-5392

DOI: $10.5433 / 1519-5392.2021 v 21 n 3 E s p . p 97$

\title{
A produção de recursos educacionais abertos na formação de professores de português como língua adicional
}

\author{
The production of open educational resources in the training of \\ teachers of Portuguese as an additional language
}

\section{La producción de recursos educativos abiertos en la formación de profesores de portugués como lengua adicional}

Fernanda Deah Chichorro Baldin ${ }^{1}$ (iD https://orcid.org/0000-0001-6187-2433

Jeniffer Imaregna Alcantara de Albuquerque 2 (iD https://orcid.org/0000-0002-1498-3680

Elisa Novaski Cordeiro ${ }^{3}$ (iD https://orcid.org/0000-0003-2876-2579

\begin{abstract}
RESUMO: Este artigo tem por objetivo contextualizar e expor o trabalho de produção de material didático como Recurso Educacional Aberto (REA) em uma das disciplinas de Ensino de Português para Falantes de Outras Línguas (PFOL), do Curso de Letras Inglês da Universidade Tecnológica Federal do Paraná (UTFPR), campus Curitiba (CT), atentando para a importância dessa produção na formação de professores de português como língua adicional. Interessa-nos discutir a relevância da educação aberta por meio de materiais que se configurem como REAs, a agência dos alunos na produção de materiais didáticos, a apropriação por parte deles desse componente na sua formação como professores, conformando, desse modo, o panorama teórico-metodológico da construção dessa disciplina. Para tanto, descrevemos como a disciplina em questão está organizada e trazemos algumas reflexões acerca da literatura e premissas que embasam a ementa desta e como o tal organização se entrelaça com a práxis do docente em formação inicial.
\end{abstract}

PALAVRAS-CHAVE: REA. PLA. Formação de professores.

ABSTRACT: This article aims to contextualize and expose the work of production of didactic material as An Open Educational Resource (OER) in one of the disciplines of teaching Portuguese for Speakers of Other Languages (PFOL), of the English Letters Course of the Federal

\footnotetext{
${ }^{1}$ Mestre em Estudos Literários pela Universidade Federal do Paraná. Professora do Magistério Superior da Universidade Tecnológica Federal do Paraná. E-mail: fernandabaldin@utfpr.edu.br

2 Doutora em Letras pela Universidade Federal do Rio Grande do Sul. Professora do Magistério Superior da Universidade Tecnológica Federal do Paraná. E-mail: jenifferalbuque@utfpr.edu.br.

${ }^{3}$ Doutora em Letras pela Universidade Federal do Paraná. Professora do Magistério Superior da Universidade Tecnológica Federal do Paraná. E-mail: elisan@utfpr.edu.br.
} 
BALDIN, F. D. C.; ALBUQUERQUE, J. I. A.; CORDEIRO, E. N.

Technological University of Paraná (UTFPR), Curitiba campus (CT), looking at the importance of this production in the training of Portuguese teachers for foreigners. We are interested in discussing the relevance of open education through materials that are configured as OERs, the students' agency in the production of teaching materials, the appropriation by them of this component in their formation as teachers, thus conforming the theoretical-methodological panorama of the construction of this discipline. Therefore, we describe how the discipline in question is organized and bring some reflections on the literature and assumptions that underlie its syllabus and how such organization is intertwined with the praxis of teachers in initial training.

KEYWORDS: OER. PAL. Teacher practices.

RESUMEN: Este artículo tiene como objetivo contextualizar y exponer el trabajo de producción de material didáctico como Recurso Educativo Abierto (REA) en una de las disciplinas de enseñanza de portugués para hablantes de otras lenguas (PFOL), del Curso de Letras Inglés de la Universidad Tecnológica Federal de Paraná (UTFPR), campus Curitiba (CT), mirando la importancia de esta producción en la formación de profesores de portugués para extranjeros. Nos interesa discutir la relevancia de la educación abierta a través de materiales que se configuran como REAs, la agencia de los estudiantes en la producción de materiales didácticos, la apropiación por parte de ellos de este componente en su formación como profesores, conformando así el panorama teórico-metodológico de la construcción de esta disciplina. Por tanto, describimos cómo se organiza la disciplina en cuestión y aportamos algunas reflexiones sobre la literatura y los supuestos que subyacen en su plan de estudios y cómo dicha organización se entrelaza con la praxis de los docentes en formación inicial.

PALABRAS CLAVE: REA. PLA. Formación de profesores.

\section{Introdução}

A elaboração e aplicação de materiais didáticos como parte da formação de professores de línguas têm crescido nos últimos anos (LEFFA; COSTA; BEVILÁQUA, 2019). Segundo os autores, é possível acompanhar mudanças constantes na área devido à alteração no meio de produção desses materiais: do impresso ao digital. Enfatizamos que tais mudanças exigem do professor investimentos em novos saberes, os quais serão discutidos ao longo deste trabalho.

Neste artigo, analisamos o modo como se estabelece a formação inicial de professores de línguas por meio da criação de Recurso Educacional Aberto (REA), mais especificamente na área de Português para Falantes de Outras Línguas (PFOL) no curso de Letras Inglês da Universidade Tecnológica Federal do Paraná, campus Curitiba (UTFPR-CT), em uma disciplina da grade curricular da referida licenciatura. Apesar de o curso ser de Letras Inglês, há nele três disciplinas que visam à aproximação de reflexões sobre a formação de professores de PFOL. Todas elas estão articuladas em termos de conteúdo e reflexões teórico-práticas e, entre seus objetivos de estudo, estão a análise e elaboração de materiais didáticos. Uma delas, como veremos, pressupõe a preparação 
A produção de recursos educacionais abertos na formação de professores de português como língua adicional

de materiais didáticos de português como língua adicional (PLA) que, preferencialmente, constituam-se como REAs.

Apesar de a área de PLA, no Brasil, encontrar-se em expansão, menos de $5 \%$ das universidades brasileiras realizam práticas de formação de professores nesse campo (LEURQUIN; SILVA, 2020). De acordo com as autoras, alguns aspectos relativos a essa questão merecem ser pontuados: a necessidade de se visualizar a língua portuguesa como foco de interesse de outros países; a falta de uma política de acolhimento a alunos e pesquisadores estrangeiros, visando à inserção social e cultural desses indivíduos; a importância de investimento em políticas que tenham como foco a produção de materiais didáticos em diferentes contextos.

Nesse sentido, ressaltamos a importância de iniciativas que visem à produção de materiais didáticos vinculadas à formação de professores. Leffa, Costa e Beviláqua (2019) levantam os aspectos positivos dessa dinâmica ao destacar a possibilidade de contextualização do material, bem como a possibilidade de atender às demandas e aos interesses da comunidade em um dado momento vivido.

Na UTFPR-CT, na área de PFOL, as três disciplinas ofertadas no curso de Letras Inglês se integram às atividades promovidas pelo Programa de Extensão Português para Falantes Outras Línguas (PFOL/UTFPR-CT), cujos objetivos principais são: oferecer aulas de português a estrangeiros que fazem parte tanto da comunidade interna quanto da externa da universidade e proporcionar a formação inicial dos acadêmicos de Letras Inglês. Dessa forma, todos os REAs produzidos são pensados a partir de contextos e demandas reais experienciadas pelos alunos estrangeiros, as quais são observadas pelos licenciandos antes da definição dos objetivos e temática do REA a ser elaborado.

Neste artigo, dividimos a exposição da pesquisa do seguinte modo: primeiramente, definimos o conceito de REA e suas principais características, em seguida, explicitamos os aspectos mais importantes para esta pesquisa relativos às disciplinas Grupo de Pesquisa PFOL, Ensino de PFOL 1 e Ensino de PFOL 2, esclarecendo os pontos que nos parecem mais relevantes no que se refere à formação de professores de PFOL e de que modo as três disciplinas dialogam entre si e, por fim, focamos nossa atenção na disciplina Ensino de PFOL 2 e na elaboração de REA como um recurso formativo.

\section{Recursos Educacionais Abertos e formação de professores de línguas}


BALDIN, F. D. C.; ALBUQUERQUE, J. I. A.; CORDEIRO, E. N.

Segundo Santos (2013), os REAs frequentemente são chamados de Objetos de Aprendizagem ou Conteúdo Aberto. De acordo com a autora, o primeiro termo foi cunhado por Wayne Hodgins em 1994, definido como "um pequeno componente instrucional que pode ser reutilizado em diferentes contextos de aprendizagem" (SANTOS, 2013, p. 21). Já o termo Conteúdo Aberto foi criado por Wiley (1998 apud Santos, 2013) e este promove a ideia de conteúdos educacionais abertos utilizados em contextos diversos e experienciados por diferentes docentes e alunos.

Santos (2013) ainda aponta duas iniciativas significativas ocorridas em 2001 que possibilitaram a ampliação do movimento REA. A primeira foi a fundação da Creative Commons (http://www.creativecommons.org), que proporciona aos detentores especificarem quais direitos desejam ceder, permitindo que usuários de conteúdos educacionais copiem, adaptem, traduzam e compartilhem recursos livremente. Em consonância com essa iniciativa, a segunda foi o Consórcio OpenCourseWare (http://www.ocwconsortium.org/), cujo intuito era envolver diversas instituições de ensino em todo o mundo a fim de fomentar o movimento REA por meio da produção de conteúdos e aconselhamento sobre políticas, promoção e pesquisa. A autora afirma que o termo Open Educational Resources (OER) foi criado durante o Forum on the Impact of Open CourseWare for Higher Education in Developing Countries, evento promovido pela UNESCO no Massachusetts Institute of Technology (MIT), em 2002. Em 2006, o termo foi traduzido para o português como Recurso Educacional Aberto (REA).

Aderimos à definição de REA trazida por Santos (2013) e, segundo a pesquisadora, aceita pela UNESCO: "recursos de ensino, aprendizagem e pesquisa que estejam em domínio público, ou que tenham sido disponibilizados com uma licença de propriedade intelectual que permita seu uso e adaptação por terceiros" (SANTOS, 2013, p. 21). É importante ressaltar, contudo, que outros materiais educacionais disponíveis na Internet gratuitamente, mas sem licença aberta, não são considerados REA. Desse modo, o que diferencia um REA de outros materiais é a licença que proporciona o seu reuso e possível adaptação, sem que o usuário necessite de autorização do autor.

Existem seis tipos de Licença Creative Commons: CCBY (permitida a distribuição, remixagem, adaptação e criação a partir do trabalho original, mesmo para fins comerciais); CC BY-SA CompartilhaIgual (permitida a remixagem, adaptação e criação a partir trabalho original, mesmo para fins comerciais, desde que se licenciem as novas criações sob termos idênticos); CC BY-ND SemDerivações (permitido o reuso para 
qualquer propósito, inclusive comercial, mas não pode ser compartilhado de forma adaptada); CC BY-NC NãoComercial (permitida a remixagem, adaptação e criação a partir trabalho original, para fins não comerciais); CC BY-NC-SA NãoComercial-CompartilhaIgual (permitida a remixagem, adaptação e criação a partir trabalho original, para fins não comerciais e licenciamento de novas produções com termos idênticos); CC BY-NC-ND SemDerivações-SemDerivados (só é permitido o download, sem compartilhamento nem alteração). Em todos os casos, exige-se que os devidos créditos sejam dados ao(s) autor(es).

Nesse sentido, Santos (2013, p. 21) ressalta que: "diversas iniciativas de conteúdo digital aberto no Brasil ainda não podem ser consideradas experiências de REA no sentido pleno. Algumas delas estão caminhando nessa direção, mas os materiais educacionais ainda não foram devidamente licenciados" Esta questão nos coloca em um impasse em relação ao ciclo de idealização, elaboração e compartilhamento dos recursos, os quais muitas vezes não chegam à fase final de serem compartilhados, uma vez que os processos de licenciamento podem ser pouco acessíveis aos envolvidos no processo de confecção do REA.

Ainda esclarecendo a definição de REA, destacamos os 4Rs sistematizados por Wiley (1998, apud Leffa, 2016) são 1) Reusar: usar o recurso tal qual ele foi proposto pelo autor; 2) Reelaborar: adaptar o recurso a suas próprias demandas e contexto; 3) Remixar: combinar um recurso com outro(s); 4) Redistribuir: compartilhar o recurso reusado, reelaborado ou remixado. Porém, Leffa (2016) destaca que, apesar de o domínio público e a possibilidade de adaptação serem características essenciais dos REAs, há outros atributos ainda pouco abordados pela literatura da área, mas que merecem atenção e, desse modo, passa a refletir sobre os elementos que compõem a sigla: por que Recurso, por que Educacional e por que Aberto?

A diferença entre recurso e objeto, segundo Leffa (2016), é a de que, enquanto o primeiro representa um meio para se alcançar um fim, transparecendo a noção de instrumento, o objeto, muitas vezes, é entendido de modo ambíguo, podendo representar tanto um artefato cultural que se torna um meio para conseguir algo (um livro, por exemplo), ou o próprio saber (uma resenha sobre o livro, por exemplo). Desse modo, o autor recorre à ideia de recurso como instrumento, trazendo o conceito de instrumento a partir da perspectiva sociocultural, recorrendo a Vygotski e à Teoria da Atividade, assim 
"o conceito de recurso adquire uma importância maior porque potencializa o sujeito, capacitando-o a fazer o que ele seria incapaz de fazer sozinho" (LEFFA, 2016, p. 361). Ainda na visão de Leffa (2016), a produção do recurso é capaz de instigar a autonomia do estudante, o qual passa a olhar para a sua prática (atual, em formação ou futura) de modo acional, mobilizando teorias e reflexões adquiridas e/ou em desenvolvimento para transformar seu espaço de atuação.

Ao passar para o conceito por trás do termo educacional, o autor define o recurso educacional como aquele que exige do aluno um envolvimento experiencial (LEFFA, 2016). Ou seja, uma música por si só não é um recurso educacional, mas perguntas sobre a letra da música, já transformam o conjunto música + perguntas em um recurso educacional. Assim, não basta o estudante ouvir a música e entender a canção, ele precisa tentar, experimentar e agir de algum modo, obtendo algum tipo de feedback.

Neste ponto, é importante refletirmos sobre a seguinte colocação do autor:

O processo de dotar um recurso com conteúdo educacional, de certo modo, didatizando-o, é sempre um empreendimento muito arriscado porque pode destruir o objeto de estudo, seja um poema, um texto de Bakhtin, um quadro famoso ou um filme cult. Isso acontece, por exemplo, quando o autor da atividade prende-se a detalhes totalmente irrelevantes, que nada contribuem para compreender a obra que está sendo discutida; em vez de trazer para o aluno aspectos essenciais de qualificação do texto, fica no pretexto de algum ponto gramatical, restringindo-se a alguma liturgia didática que tem como principal consequência desmotivar o aluno. A tese, defendida aqui, é de que com o domínio dos recursos digitais, hoje disponíveis, a produção de conteúdo educacional ficou mais viável, interessante e criativa, ainda que não necessariamente mais fácil (LEFFA, 2016, p. 363).

A partir do exposto pelo autor, passamos a compreender um pouco mais acerca da indissociabilidade entre o recurso didático, sua interação com os atores (quem produz e quem utiliza o recurso) e o possível efeito nos espaços nos quais ele passa a ser utilizado.

O último elemento da sigla REA, aberto, traz consigo não apenas a ideia de gratuito, como também de adaptativo. Neste sentido, Leffa (2016) propõe os 3A: $A=A$ $+\mathrm{A}$, ou seja, Abertura = Acesso + Adaptação. $\mathrm{A}$ ideia de abertura como acesso representa o domínio público do recurso, sem qualquer tipo de restrição, seja ela operacional, financeira ou geográfica. No que se refere à operacionalidade, significa que o recurso pode ser acessado por qualquer usuário, a partir de qualquer dispositivo, seja 
um smarthphone, um tablet, um netbook, um computador de mesa e mesmo a TV. Em relação ao financeiro, o ideal seria não somente que o recurso educacional seja gratuito, mas que também haja condições de acesso digital a todos os usuários. E, por fim, no tocante a aspectos geográficos, é importante que associemos o REA a um processo de democratização e acesso a recursos didáticos de qualidade, conectando pessoas ou comunidade mais isoladas dos grandes centros com os materiais produzidos e distribuídos digitalmente por todas as partes do mundo.

\section{O Português como Língua Adicional no Curso de Letras Inglês da UTFPR-CT}

O PFOL passou a ser componente curricular na licenciatura em Letras na UTFPRCT, em 2016, quando o Curso de Letras Inglês foi implementado. Antes disso, ele já figurava na extensão e estava relacionado à formação de professores, embora restrito aos estudantes que mostravam interesse por essa formação, uma vez que não constava do rol de disciplinas do curso em andamento até então (Letras Português Inglês) - nem em optativas.

A idealização do então novo Projeto de Curso (Letras Inglês) realizou-se durante 2014 e 2015, em meio a discussões de internacionalização da universidade, cujos discursos fomentaram o debate do novo currículo. O Idiomas sem Fronteiras (IsF), programa governamental do qual a UTFPR fazia parte, possibilitava a discussão não só da necessidade de formação de professores de inglês e, consequentemente, ampliação da proficiência de alunos e servidores da instituição, mas dava margem para que debates sobre o português como língua adicional tivessem lugar.

Concomitante a esse período, na extensão, em 2016, o PFOL/UTFPR-CT era um Projeto e, em 2018, dada a importância das atividades desenvolvidas institucionalmente, também então com ações integradas oficialmente ao Curso de Letras Inglês, tornou-se Programa de Extensão, o que conferiu compromisso institucional em sua manutenção por, pelo menos, quatro anos.

Além desse aspecto, consideramos outros dois fortes motivos para que a inclusão do PFOL como componente curricular em Letras Inglês pudesse ocorrer: a visão da coordenadora do Curso à época e também catalisadora acerca das discussões sobre o novo PPC, que vislumbrava a possibilidade de nos adiantarmos no planejamento de um curso de Letras que pudesse vir a ser realizado por estrangeiros, com a potencial oferta 
de cinco níveis de português como língua adicional, aproveitando em parte o trabalho já realizado na extensão (o que faria com que o curso, com algumas modificações, pudesse ser de licenciatura dupla Inglês - PFOL); e as próprias ações já realizadas na extensão, que contavam com a oferta semestral de cursos livres de português para estrangeiros tanto da comunidade interna quanto externa - e grupo de trabalho e de pesquisa para formação de professores, sendo essa última atividade geradora de investigações que culminaram em apresentações de comunicações em eventos da área e, ainda, na produção de vários Trabalhos de Conclusão de Cursos (TCCs).

Dessa maneira, foram incluídos dois componentes curriculares obrigatórios no Curso - Ensino de PFOL 1 e 2, respectivamente no $5^{\circ}$ e $6^{\circ}$ períodos, em um total de oito períodos letivos. Além destes, outro componente intitulado Grupo de Pesquisa em PFOL (GPPFOL) é ofertado para alunos matriculados a partir do segundo semestre do Curso, entre um rol de opções de Grupo, a partir do qual o aluno deve optar. ${ }^{4}$ Cada um desses componentes tem carga horária de $72 \mathrm{~h}$.

No Ensino de PFOL 1, o objetivo é apresentar a área de PLA, partindo do nosso contexto imediato - o Programa de Extensão PFOL da UTFPR-Campus Curitiba - e relacionando-o à organização da área tanto no Brasil como no exterior. Para isso, discutimos conceitos de língua $\mathrm{e}$ interculturalidade, presentes em documentos orientadores em Portugal e no Brasil; discutimos o português como língua pluricêntrica e algumas políticas linguísticas, como o Portal do Professor de Português Língua Estrangeira/Não Materna, tratando de promover uma visão crítica à análise de materiais do Portal ao discutir conceitos de língua, plurilinguismo e interculturalidade. Refletimos ainda sobre questões de ensino de português em contextos de imersão e não imersão, centrando a aprendizagem nos sujeitos, nos grupos e nas suas práticas sociais realizadas e almejadas e analisando materiais didáticos diversos para públicos diferentes, extraindo destes a perspectiva de língua adotada.

Em Ensino de PFOL 2, foco do presente artigo, questões de cultura e de interculturalidade são retomadas teoricamente para que sua presença seja analisada em

\footnotetext{
${ }^{4}$ Os Grupos de Pesquisa, como componente curricular, são projetos integradores e que em sua práxis operam como grupos de pesquisa, caracterizando-se pela possibilidade de os alunos entrarem em contato com diferentes áreas de estudo e realizarem uma pequena pesquisa durante o semestre letivo. Essa investigação é apresentada ao final de cada período em um simpósio interno do Curso de Letras Inglês. Os professores que fazem parte dos Grupos de Pesquisa revezam-se no oferecimento da disciplina e nem sempre há oferta dos mesmos grupos, o que acontece por revezamento já que os alunos devem cursar obrigatoriamente cinco grupos (do $2^{\circ}$. ao $6^{\circ}$ períodos) sem repetir nenhum deles. Desde o início do Curso, o GPPFOL foi ofertado cinco vezes.
} 
materiais didáticos diversos. A partir de análises de materiais didáticos, há reflexão sobre mercado editorial, direitos autorais e REAs, para, então, considerando práticas sociais como base para a noção de língua, propor-se o planejamento e a construção de unidades didáticas de PLA, preferencialmente que se configurem como REA (cujos conceitos e motivações estão explicitados na seção 4 deste artigo).

Apesar de nenhum dos componentes curriculares terem pré-requisito, 0 observado, até o momento, é que grande parte dos alunos cursam Ensino de PFOL 1 antes de Ensino de PFOL 2, o que já Ihes confere uma base para análise mais acurada de materiais didáticos, para, então, organizar práticas autorais. Um dos objetivos é que os alunos conscientizem-se (ainda mais) de seu papel agentivo em relação ao planejamento das aulas. Planejar as aulas implica também a seleção dos materiais que serão usados e os modos de mobilização destes. Traçar uma possibilidade de caminho para ensino de línguas e materializá-lo em unidades didáticas, por exemplo, pode conferir ao estudante maior responsabilidade em relação a processos de ensino aprendizagem e também consciência de seu papel político durante as aulas.

\section{Ensino de PFOL 2: produção de materiais didáticos como recursos educacionais}

Conforme discutido nas duas seções anteriores, a disciplina de Ensino de PFOL 2, que compõe a grade dos licenciandos em Letras Inglês, possui como foco a análise e elaboração de materiais didáticos. Tais recursos são realizados a partir de pequeno conjunto de atividades ou unidades didáticas, que se caracterizam, como apresentado na seção anterior, de preferência, como REAs 5 .

É possível delinear a organização da disciplina em dois momentos: i) reflexão sobre conceitos relacionados ao construto de identidade e um processo de elaboração de materiais didáticos via abordagem intercultural (GIMENEZ, 2005; HALL, 2006; MENDES, 2012); ii) elaboração dos recursos didáticos, a partir das reflexões e modo de organização em etapas de produção de materiais didáticos de Leffa (2003).

Acerca da primeira etapa, os licenciados continuam um trabalho iniciado na

\footnotetext{
${ }^{5}$ Em geral, há um grande incentivo para que os alunos elaborem REAs, no entanto, nas duas edições da disciplina, as quais foram ofertadas em 2020/2 e 2021/1 de forma remota em razão da pandemia, foi aberta a possibilidade de os alunos realizarem REAs com todos os critérios elencados por Leffa (2016, cf. discussão apresentada na seção 1) ou como REAs parciais (de modo que nem todos os elementos do material se encontravam em domínio aberto).
} 
disciplina de Ensino de PFOL 1, de modo a refletir sobre suas identidades enquanto sujeitos da modernidade/pós-modernidade. São feitas diversas reflexões sobre o 'ser brasileiro' e 'ser falante de português' para que os estudantes percebam que suas identidades também se encontram em trânsito, que não são fixas/estáticas. Os alunos são convidados a anotarem suas impressões a partir das discussões, as quais são sempre feitas exemplificando como os materiais de PFOL (livros, apostilas publicadas e os REAs já produzidos pelas turmas anteriores dentro do Programa do PFOL) trazem essas questões da identidade brasileira. A expectativa é que, posteriormente, os alunos utilizem essas observações para realizarem escolhas mais informadas de elementos visuais e audiovisuais que utilizarão em seus recursos.

Em relação à segunda etapa, trazemos uma releitura de Miyamura (2009, apud FURTOSO, 2014) feita por Viviane Furtoso. A autora comenta que o primeiro passo para a construção de um planejamento de curso seria se pautar nas necessidades dos alunos/do público-alvo para o qual o material será destinado e que, posteriormente a esse momento, seriam delineados os objetivos do curso para que, então, os conteúdos a serem ministrados nele sejam selecionados e organizados. Leffa (2003) também propõe um processo semelhante para a criação de materiais didáticos, indicando que a elaboração se inicie a partir das necessidades dos alunos e que os objetivos criados sejam de aprendizagem e não de ensino, ou seja, o autor faz uma crítica acerca do fato de que a maioria dos recursos didáticos tem como fim último objetivos que favoreçam mais o professor do que os alunos.

O ciclo proposto pro Miyamura (2009, apud FURTOSO, 2014) possui outras etapas que não traremos para esta discussão. Interessa-nos, contudo, apontar que ao elaborarem os REAs, os alunos são convidados a pensar como os recursos didáticos se inserem dentro de um planejamento de curso, dentro de um ciclo que se retroalimenta. Nos é caro ponderar que ambos os grupos, professores em formação inicial e continuada, precisam compreender a impossibilidade de elaborar materiais que atendam a todos os contextos e diferentes demandas dos alunos estrangeiros. Neste sentido, parece-nos que um dos maiores argumentos em prol a elaboração e utilização de REAs advém de sua constituição enquanto materiais de base, abertos e passíveis de modificação.

Assim, ao assumirmos esse olhar para os materiais didáticos, adotamos o ciclo de quatro etapas de produção de material didático, proposto por Leffa (2003), a saber: 1) Levantamento das necessidades dos alunos; 2) Desenvolvimento, que envolve a 
elaboração dos objetivos de aprendizagem; 3) Implementação; 4) Avaliação.

Em razão da duração do semestre, 72 horas, não se apresenta como viável a implementação de todos os recursos produzidos pelos alunos. Assim, para a primeira etapa, de levantamento das necessidades, os alunos de Letras Inglês são convidados a assistirem/acompanharem algumas aulas de PFOL, oferecidas durante os cursos de extensão, abertos à comunidade externa da universidade. Os alunos fazem anotações e observam aspectos que possam ser de interesse de aprendizagem dos aprendizes de português. Após realizarem as observações, os alunos agendam reuniões individuais com a professora da disciplina para socializar as demandas observadas e rascunhar as primeiras ideias de organização do material didático. Os alunos são, então, convidados a realizarem pequenas entregas do material, sendo a primeira etapa um esqueleto da unidade, juntamente com os objetivos de aprendizagem (os quais podem mudar e, efetivamente, modificam-se, ao longo da elaboração do material).

Conforme apontamos anteriormente, ao elaborarem recursos didáticos, especialmente REAs, procuramos construir um caminho para o ensino de línguas que se baseie na práxis diária do professor, utilizando o processo de elaboração de materiais didáticos como uma materialização dessas reflexões, demandas e possibilidades de ação. Entendemos a elaboração de REAs como um exercício político da prática do professor de línguas e, como tal, é importante que o ciclo se volte para os demais alunos do curso, que ainda cursarão a disciplina de Ensino de PFOL 2. Assim, ao final do semestre, os alunos realizam uma apresentação da unidade para os colegas e são convidados a, no semestre seguinte, compartilharem suas unidades com os colegas que ainda estão passando pelas reflexões da disciplina.

\section{Reflexões sobre a produção de REA e a formação de professores de PFOL}

A formação de professores de PFOL a partir da elaboração de REAs prevista na disciplina Ensino de PFOL 2 se sustenta no tripé universitário: ensino, pesquisa e extensão, uma vez que envolve as três dimensões por meio da participação dos alunos da disciplina no Programa de Extensão PFOL/UTFPR-CT. Esses estudantes, como já mencionado, passam primeiramente pela disciplina Ensino de PFOL 1, na qual têm contato com um panorama geral de estudos na área de PFOL (relativos a ensino, aprendizagem, interculturalidade e identidades). Na disciplina seguinte, Ensino de PFOL 
2, no princípio do semestre letivo há encontros semanais com toda a turma para discutir conceitos e visões teóricas no que se refere à produção de materiais didáticos, em especial REAs, concomitantemente, eles acompanham as aulas de PFOL nos cursos de extensão oferecidos a estrangeiros da comunidade externa e interna da UTFPR-CT. A partir desse acompanhamento, eles observam o modo como as interações se dão, tanto durante as aulas síncronas (seja no modelo presencial ou remoto), como nas interações via grupos de WhatsApp das turmas.

A partir dessas primeiras observações, eles produzem materiais, na sua maioria REAs, tendo em vista o perfil de uma turma específica, levando em conta suas dificuldades e necessidades. Essa adequação às particularidades da turma é essencial para que o material produzido faça sentido para um grupo de alunos especificamente. Como aponta Leffa (2003, p. 16):

A análise parte de um exame das necessidades dos alunos, incluindo seu nível de adiantamento e o que eles precisam aprender. As necessidades são geralmente mais bem atendidas quando levam em consideração as características pessoais dos alunos, seus anseios e expectativas, preferência por um ou outro estilo de aprendizagem. Para que a aprendizagem ocorra é também necessário que o material entregue ao aluno esteja adequado ao nível de conhecimento do conteúdo a ser desenvolvido (LEFFA, 2003, p. 16)

Assim, a produção de REAs pelos alunos da disciplina Ensino de PFOL 2 é possível graças à sua articulação com a extensão. Outro ponto a ser levantado é a questão da troca de conhecimentos entre alunos que já passaram pela disciplina e tiveram a oportunidade de desenvolver materiais didáticos (entre eles, REAs) e alunos que estão cursando atualmente. A apresentação e análise de materiais já produzidos pelos colegas confere interação e trocas de experiências entre os formandos. Leurquin e Silva (2020), em sua pesquisa sobre a relação entre produção/análise de material didático e formação de professores de língua, apontam esse movimento como uma proposta de rompimento com o velho paradigma baseado em uma suposta homogeneidade para a sala de aula, o que não permite que o professor não considere as particularidades de sua turma.

\section{Considerações finais}

As reflexões aqui apresentadas partem do chão da sala de aula, o qual se constitui como espaço simbólico e concreto para produção de conhecimento e de práticas mais autônomas dos estudantes. Assim, eles podem passar a olhar para sua prática de modo 
A produção de recursos educacionais abertos na formação de professores de português como língua adicional

ativo, resgatando teorias e reflexões adquiridas e/ou em desenvolvimento para transformar seu espaço de atuação.

Dessa forma, reiteramos as vantagens de promover o exercício de elaboração de REAs atrelado aos conteúdos de uma disciplina que visa à formação de professores de língua, mais especificamente de PFOL. A produção de REA, portanto, ajuda o licenciando a: 1) entrar em contato com alunos reais em uma situação real de aprendizagem; 2) planejar e elaborar seu material a partir do perfil e das particularidades de uma turma real; 3) pesquisar, selecionar e adequar materiais já existentes e produzidos por outros professores, a partir de uma realidade específica; 4) colaborar com a produção de materiais didáticos de PFOL e disponibilizá-los em rede.

Esperamos que esta reflexão possa mobilizar boas práticas nos espaços de formação de professores de línguas, em especial de PLA, de modo que a análise, produção e aplicação de REAs possam ser vista como parte de uma formação informada de professores que veem o material didático aberto como uma ponte para uma educação mais inclusiva.

\section{Referências}

FURTOSO, Viviane Aparecida Bagio. Português para falantes de outras línguas: pesquisa, ensino e formação de professores. Curitiba: UFPr, 2014. Apostila usada em disciplina de Programa de Pós-Graduação em Letras da Universidade Federal do Paraná.

GIMENEZ, Telma Nunes. Desafios contemporâneos na formação de professores de línguas: contribuições da linguística aplicada. In:: FREIRE, Maximina; ABRAHÃO, Maria Helena Vieira; BARCELOS, Ana Maria Ferreira (Orgs). Linguística aplicada e contemporaneidade. Campinas: Pontes, 2005.

HALL, Stuart. A identidade cultural na pós-modernidade. Traduação: Tomaz Tadeu da Silva e Guacira Lopes Louro. 11. ed. Rio de Janeiro: DP\&A, 2006.

LEFFA, Vilson J. Como produzir materiais para o ensino de línguas. In: LEFFA, Vilson J. (org.). Produção de materiais de ensino: teoria e prática. Pelotas: Educat, 2003. p. 15 a 41.

LEFFA, Vilson J. Uma outra aprendizagem é possível: colaboração em massa, recursos educacionais abertos e ensino de língua. Trabalhos de Linguística Aplicada, Campinas, n. v. 55, n. 2, p. 353-377, maio/ago. 2016.

LEFFA, Vilson J.; COSTA, Alan Ricardo; BEVILÁQUA, André Firpo. O prazer da autoria na elaboração de materiais didáticos para o ensino de línguas. In: FINARDI, Kyria Rebeca et al. (org.). Transitando e transpondo n(a) linguística aplicada. Campinas: Pontes, 
2019, p. 267-297.

LEURQUIN, Eulália Vera Lúcia Fraga; SILVA, Meire Celedonio; Gondim, Ana Angélica Lima. Formação de professores de PLE: análise e produção do material didático como estratégia. Textura, Canoas, v. 22, n. 52, p. 197-215, out./dez. 2020.

MENDES, Edleise. O conceito de língua em perspectiva histórica: reflexos no ensino e na formação de professores de português. In: LOBO, Tania et al. (org.). ROSAE: linguística histórica, história das línguas e outras histórias. Salvador: EDUFBA, 2012. p. 667-677.

SANTOS, Andreia Inamorato dos. Recursos educacionais abertos no Brasil: o estado da arte, desafios e perspectivas para o desenvolvimento e inovação. São Paulo: Comitê Gestor da Internet no Brasil, 2013.

Submetido em: 01 out. 2021. Aceito em: 19 out. 2021. 